Rosario Camacho Martínez

SECRETARIO

Juan Antonio Sánchez López

CONSEJO DE REDACCIÓN

Natalia Bravo Ruiz

Eugenio Carmona Mato

Isidoro Coloma Martín

Reyes Escalera Pérez

Francisco J. García Gómez

$M^{a}$ de la O Heredia González

$M^{a}$ Teresa Méndez Baiges

Aurora Miró Domínguez

Juan Ma Montijano García

José Miguel Morales Folguera

F. Javier Ordóñez Vergara

Francisco J. Palomo Díaz

Eva Má Ramos Frendo

Francisco J. Rodríguez Marín

Nuria Rodríguez Ortega

Belén Ruiz Garrido

Rafael Sánchez-Lafuente

María Teresa Sauret Guerrero

DISEÑO Y MAQUETACIÓN

Sonia Ríos Moyano

VINETTA DE LA PORTADA

Alonso Cano: Proyecto de

Tabernáculo (h. 1665).

Biblioteca Nacional (Madrid)

Homenaje a Alonso Cano en el

IV Centenario de su nacimiento

(1601-2001)

Esta revista es analizada por el centro de Información y Documentación Científica del C.S.I.C. e incluídas en la B.D.I.S.O.C.

EDITA: Departamento de Historia del Arte de la Facultad de Filosofía y Letras Servicio de Publicaciones de la Universidad de Málaga

Impreso en Andalucía

I.S.S.N.: 0211-8483

Depósito Legal: MA-1.554-2001 
: Boletín de Arte, no $22-2001$

Departamento de Historia del Arte

Universidad de Málaga

219
Antonia Robles Robles

Eva Ma Ramos Frendo

Tomás Galicia Gandulla

Ma Pilar Díaz Ocejo/ Mercedes Luque Nieves

Lourdes Moreno

Francisca Pastor Pérez I

Macarena Recio Bueno

Irene García Antón

Alfonso Ruiz García
Escenografía teatral, festividad y decoración: el dogma de la Inmaculada y su proclamación en la Roma de Pio IX

Los hermanos Díaz de Escovar, dos malagueños dedicados al impulso cultural a través de sus colecciones

El cambio de gusto en la temática pictórica en el tránsito del siglo $\mathrm{XIX}$ al $\mathrm{XX}$ a través de la prensa

La Fábrica de Tabacos de Málaga.

Estudio histórico-artístico de un símbolo de nuestro pasado industrial

Una figura clave para la ilustración española de principios de siglo XX: Francisco Sancha

Los jardines de

Pedro Luis Alonso de Málaga

Un cuarto de baño privado. Fantasía ecléctica y reclamo publicitario

Modernismo e Historicismo arquitectónico:

Delegación de la Consejería de Educación en Cortijo Fischer (Almería)

El Perchel malagueño en la pintura de López Palomo

Grupo Picasso de Málaga (1957-1964) 


\title{
El Perchel malagueño en la pintura de López Palomo
}

\author{
José Manuel Sanjuán López
}

El presente trabajo plantea una panorámica global acerca del tratamiento pictórico que el castizo barrio malagueño del Perchel, y particularmente sus rincones y espacios urbanos, reciben en la obra de Rafael López Palomo, cuyas composiciones hacen gala de un peculiar figurativismo con sugestiones de estirpe cubista.

This article studies the urban pictorial representations dedicated by Rafael López Palomo to some perspectives of popular town ward of "Perchel" in Málaga. These paintings are figurative compositions with some cubist flashes.

En una columna periodística aparecida el veinte de agosto de 1977, en el diario Sur de Málaga, el responsable de la misma, Baldrich, quiso retratarse junto a un cuadro de formato apaisado que representaba un paisaje urbano. Dicha obra, titulada Casas viejas, había sido premiada con un segundo galardón en el II Concurso Nacional de Pintura "Museo Cruz Herrera», celebrado en la Línea de la Concepción. Aunque no lo dice, Baldrich, cuya pose introspectiva nos delata su admiración por la obra, se siente fascinado ante ese grupo de casas a medio derruir que parecen descubrirnos una suerte de armonía silenciosa y comedida'.

Dos años más tarde, el mismo lienzo figuró como portada en el catálogo de la exposición de su autor, Rafael López Palomo (Málaga, 1942), en la Galería Miramar Arte, de la capital malagueña ${ }^{2}$. En esa ocasión, el nombre cambia a Perchel, con el ánimo de reflejar su exacta ubicación, pero lo que no varía es la ineludible sensación de que somos testigos de un lienzo complejo, enigmático, de una aparente simplicidad formal que, a la menor pesquisa por nuestra parte, constata un depurado proceso mental y una estudiada ejecución que, en el pintor que nos ocupa, son una constante en su labor pictórica.

Desde su primera exposición individual, en 1962, López Palomo ha practicado una figuración heterodoxa que aplica con preferencia en paisajes rurales y urbanos, así como en bodegones e interiores, sin olvidar su faceta dibujística en la que

SANJUÁN LÓPEZ, José Manuel: «El Perchel malagueño en la pintura de López Palomo», en Boletín de Arte, nº 22, Universidad de Málaga, 2001, págs. 375-390. 
también aparece, como tema preferente, la figura humana. Con frecuencia, la crítica ha ponderado tanto el colorido como la preocupación hacia el contenido social de los temas $^{3}$. Aquél, heredado del luminismo tardío de tradición local, alcanza su más brillante dicción expresiva mediante el binomio luz/color, con una factura resueltamente moderna. El denominado "contenido social» proviene de una etapa, que abarca aproximadamente desde 1970 a 1980, donde el pintor prodiga sus visitas (conviene recordar que esta es, en primera instancia, una pintura al aire libre con posterior maduración y acabado en estudio) hacia barrios populares, consagrados por el tipismo y con un futuro incierto a medio plazo ante el avance feroz de la especulación urbanística.

Antes de comentar la selección de obras representativas de este período, debemos exponer, aunque de forma somera, la peculiar idiosincrasia de este célebre barrio malagueño, y las posibles causas de su evidente atractivo pictórico, no sólo para López Palomo, sino también para otros artistas locales, tales como Perdiguero o Manuel Garvayo, que, por esas mismas fechas, y cada uno en su estilo, destinaban parte de su producción para testimoniar la realidad allí percibida; una realidad que, como veremos en el pintor que nos ocupa, no se identifica necesariamente con la imagen típica del lugar.

La zona conocida como el Perchel y la Trinidad constituía desde época islámica uno de los dos arrabales que la ciudad poseía fuera de las murallas, donde, conforme a pautas musulmanas, la población se agrupaba de acuerdo con sus oficios y medios de vida ${ }^{4}$. Más próximos a la costa, en los percheles se aglutinaban las actividades pesqueras (que tomó su nombre de las perchas donde se salaba el pescado), mientras que las faenas agrícolas se situaban en torno a las huertas que después ocuparía el convento de la Trinidad. A partir de 1786, con la total demolición de las murallas, ya superadas con anterioridad, comenzó un amplio ensanche hacia el sur, por lo que el Perchel y la Trinidad quedaron unidos formando una amplia ciudad al otro lado del río. En el siglo XX, los grandes Planes de Reforma $(1923,1929)$ intentaron paliar sin éxito los graves problemas estructurales de este enclave, e incluso, en 1984, con el nuevo Plan General de Ordenación Urbana, se redactó un Proyecto de Rehabilitación de los barrios de la Trinidad y el Perchel, que tampoco llegó a buen término ${ }^{5}$.

${ }^{1}$ S. a. «Rafael López Palomo, un impresionismo desnudo». El punto de las artes. Madrid, febrero 1992.

${ }^{2}$ Catálogo de la exposición «López Palomo». Málaga, Galería Miramar Arte, del 6 al 21 de febrero de 1979.

${ }^{3}$ AA.VV., Gran Enciclopedia de Andalucía. Sevilla, Ediciones Anel, 1979, pág. 2305.

${ }^{4}$ CHUECA GOITIA, Fernando; Breve historia del urbanismo. Madrid, Alianza Editorial, 2000, pág. 83.

${ }^{5}$ AA.VV,. Guía histórico-artística de Málaga. (dir. Rosario Camacho), Málaga, Ed. Arguval, 1992. págs. 18-52. 
Si nos basamos en los datos sociodemográficos de 1981: zona proletaria periférica, densidad poblacional superior a la media, acusada incidencia en el sector inferior de los servicios y bajo nivel cultural ${ }^{6}$, podemos imaginarnos, sin ningún esfuerzo, cien años atrás, el particular microcosmos que constituía esta zona situada al oeste de la ciudad. Además de la industria conservera del pescado y la salazón, muy apreciada desde la época romana ${ }^{7}$, otra de igual o mayor importancia era la fabricación y comercio del vino, razón por la que se fundaron varias bodegas y, sobre todo, florecieron las tabernas, que propiciaron el acercamiento de gentes variopintas y de diversa condición: charlatanes, dentistas callejeros, pitonisas, traperos, delincuentes de toda laya como menosos y valientes, y, por supuesto, jabegotes ${ }^{8}$. En fin, una galería de tipos pintorescos e historias desgarradas circulaban por la ciudad y encendían, aún más, la imaginación de los escritores, quienes, con su pluma, forjaron el mito artístico y literario del Perchel y fijaron en la memoria colectiva la imagen de barrio castizo y tradicional malagueño, cuyos personajes, protagonistas de lances heroicos o quebrantos inconfesables, brindaron un escenario idóneo para sus más adecuados transmisores: pintores y literatos. No sería justo, por otra parte, finalizar esta descripción sin afirmar que esos literatos, burgueses y costumbristas en su mayoría, como González Anaya, Arturo Reyes, Ángel Caffarena o «Paco Percheles» entre otros, resaltaron el tipismo y la "gracia» de percheleros y trinitarios para ocultar la otra realidad: unas gentes descontentas de su paupérrima situación y de su completo abandono, sin que las autoridades atendieran, siquiera mínimamente, sus reivindicaciones sociales.

Sin embargo, el Perchel que López Palomo encontró en sus numerosas salidas pictóricas no se correspondía con el que acabamos de relatar. En los años setenta, el enclave estaba en pleno proceso de transformación urbanísticas: la casi totalidad de las industrias que le proporcionaron fama antaño, bien habían quebrado, bien habían desaparecido; los habituales "corralones" de vecinos, salvo casos muy puntuales, se hallaban prácticamente irreconocibles ${ }^{10}$. El resultado era harto

${ }^{6}$ LÓPEZ CANO, Damián; Sociodemografía de los barrios malagueños. Col. Textos Urbanos 1, Edita Ayuntamiento de Málaga, 1984, págs. 115 y sig.

${ }^{7}$ GUILLÉN ROBLES, F; Historia de Málaga y su provincia. (ed. Fac. Imprenta de Rubio y Cano , Málaga, 1874) Tomo I, Málaga, Ed. Arguval, 1985, pág. 52.

${ }^{8}$ FERNÁNDEZ RIVERO, Juan Antonio y ALBUERA GUIRNALDOS, Antonio; Málaga hace un siglo. Vida social y costumbres. Málaga, Prensa Malagueña, S.A., 2000, págs. 93-103.

9 A partir de los años 70 se empiezan a plantear los temas de rehabilitación de los centros históricos, siendo los Colegios de Arquitectos uno de los colectivos que más incidieron en la cuestión. MONTOYA MORENO, Carlos, «Arquitectura desde 1950 hasta nuestros días» en Medio siglo de vanguardias. Col. Historia del Arte en Andalucía, Sevilla, Ed. Gever, 1994, pág. 200.

${ }^{10}$ La vivienda de corralón es, es esencia, un bloque de pisos de dos plantas, volcadas hacia un patio central. Su distribución era la siguiente: los pisos constaban de una o, a lo sumo, dos habitaciones; tenían las instalaciones mínimas para una cocina; el agua se obtenía de un depósito situado en el patio, donde estaban un pozo negro y unos retretes comunes. El hacinamiento y el desaseo del corralón podían presentar una estampa realmente patética, tal 
elocuente: naves industriales abandonadas, locales desvencijados, viviendas semiderruidas, calles inhóspitas... un panorama desolador pero con un inmenso potencial plástico basado en juegos de sombras, construcciones volumétricas y colores contrapuestos, todo un sinfín de posibilidades para quien sabe ver en los despojos del tiempo ${ }^{11}$.

Aunque nos constan obras de temática perchelera antes de $1970^{12}$, el grueso de su producción comienza a partir de esa fecha, con lo que los óleos que aquí vamos a analizar (y que alterna con otros géneros) abarcan toda la década hasta 1980, cuando su interés por el Perchel disminuye considerablemente y afloran nuevos motivos pictóricos y diferentes tratamientos técnicos. Para el estudio de los cuadros, hemos prescindido de la clasificación cronológica por estar suficientemente acotados en el tiempo, y se ha optado por una subdivisión temática, "Panorámicas» y "Casas aisladas", si bien conforme nos acerquemos a los años ochenta su estilo evolucionará hacia una disolución de las formas y añadirá un nuevo punto de vista en el repertorio citado: calles solitarias e intemporales.

El primer rasgo que advertimos en el conjunto de su producción es la total ausencia de elementos folclóricos o costumbristas. Rehuye cualquier aditamento populista o literario de los muchos establecidos por la tradición pictórica, no sólo malagueña sino también andaluza, presentes hasta bien entrado el siglo veinte ${ }^{13}$. Descarta, así pues, tópicos recurrentes como escenas de galanteos, coloristas tejados a dos aguas con paredes blanquísimas, marengos ataviados al uso, gitanos postulantes o manolas con fingido aire despreocupado. Al eliminar el carácter anecdótico de la narración, el pintor centra su atención en las casas del entorno, unas apuntaladas y otras medio derruidas, pero todas ellas abandonadas por unos ocupantes que nunca aparecen en el lienzo, aunque se presienten. El crítico M. Urbano, de Jaén, ha descrito con sabiduría esa atmósfera queda y sosegada: En sus paisajes urbanos tan repletos de silencio, como ausentes de innecesarias anécdotas, encontramos un mundo de vivencias, de pálpitos, de vida

así, que Martínez Barrionuevo lo denomina gran claustro de la miseria. ALBUERA

GUIRNALDOS, Antonio, Vida cotidiana en Málaga a fines del XIX. Málaga, Editorial Ágora, 1998, pág. 281.

${ }^{11}$ En el momento de redactar este trabajo, febrero-mayo 2001, la zona más próxima al mar, conocida como el Perchel antiguo, sólo presenta restos de naves industriales abandonadas y desvencijadas. Tras cruzar la Prolongación de la Alameda, las viviendas típicas han sido derribadas en favor de un solar para aparcamientos; solamente algunas construcciones perviven , aunque en estado muy ruinoso, como vestigios latentes de un pasado no lejano.

${ }^{12}$ Catálogo de la exposición «Rafael López Palomo». Málaga, Sociedad Económica de Amigos del País, febrero de 1967. Por otra parte, un año antes, en 1966, le correspondió un primer premio en el concurso «Rincones Malagueños, Temas del Perchel», por lo que, definitivamente, el motivo no le era ajeno.

${ }^{13}$ QUESADA, Luis; La vida cotidiana en la pintura andaluza. Sevilla, Ed. Fundación de Cultura de Sevilla, 1992, passim. 


\section{Perchel. \\ Col. Particular \\ (Málaga), 1970}

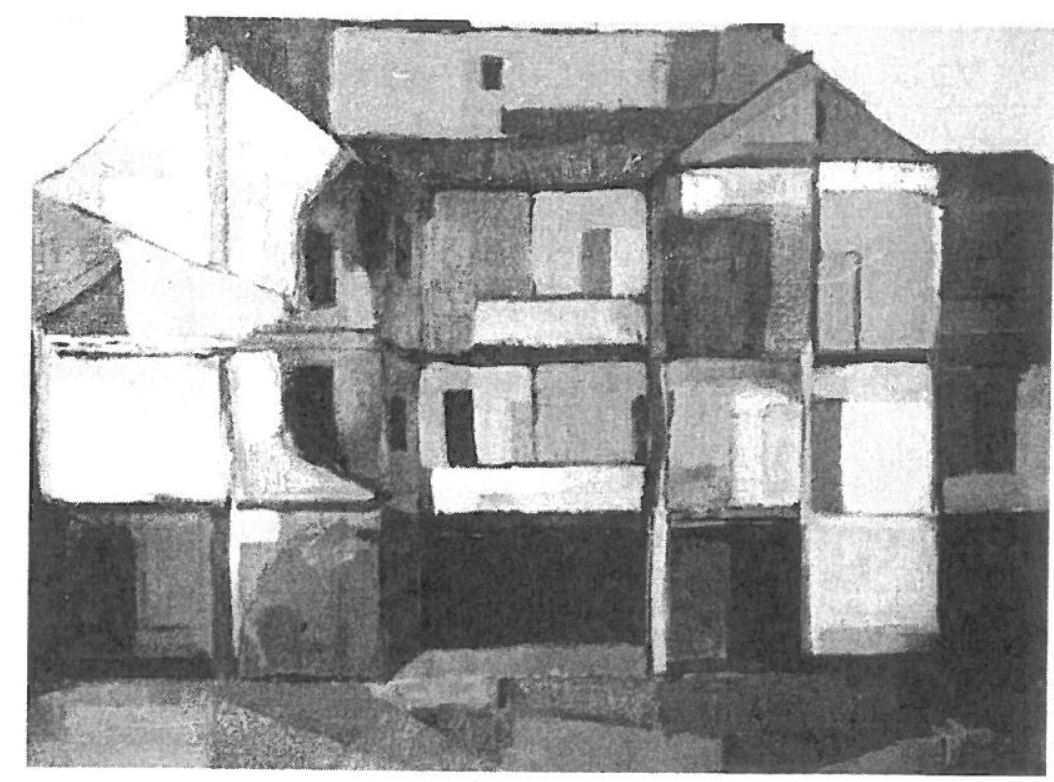

$y$ actualidad $^{14}$. Así es, el pintor no capta la vivencia actual, sino lo que fue. Los vestigios de unas vidas reflejados en paredes desconchadas, vigas que traban muros inestables o los rectángulos multicolores de lo que habían sido habitaciones; una sucesión de factores que fomentó su vinculación, animada por algunos periodistas, hacia la crítica social.

Sin embargo, en modo alguno era así. En una entrevista posterior, el propio López Palomo se encargaba de desmentirlo: No, no me considero un pintor social. Los lugares escogidos me sirven de pretexto únicamente, aunque existan críticos que puedan pensar lo contrario ${ }^{15}$. A decir verdad, y tras estudiar ulteriores series temáticas del pintor ( $\mathrm{Vg}$. pueblos de la Alpujarra granadina o interiores con macetas y plantas), coincidimos con esta apreciación en tanto que si bien retrata la imagen externa de un barrio marginal, esa imagen ha sido depurada de un naturalismo descarnado propio de artistas afines al realismo social como Manuel López Villaseñor, ni tampoco ofrece una iconografía comprometida e hiriente al estilo de Estampa Popular. El mensaje es claro: Mi intención —continúa López Palomo- ha sido la de buscar en lo temático todo lo que más se aleje de lo vacuamente decorativo $^{16}$, es decir, el motivo es un pretexto para, tras horadar la materialidad de las cosas, buscar la esencia de lo representado: las casas que el pintor nos presenta en el Perchel son despojadas de los sucesivos estratos vivenciales y, eliminado su

\footnotetext{
${ }^{14}$ Cita recogida en Catálogo de la exposición «López Palomo». Granada, Sala de Exposiciones de la Caja General de Ahorros y Monte de Piedad de Granada, del 6 al 16 de diciembre de 1980.

${ }^{15}$ ALCALÁ, Rafael, «Entrevista a Rafael López Palomo». El Parnaso. Revista Literaria de Correos y Telégrafos, Málaga, año V, núm. 25, 1989, pág. 21.

${ }^{16}$ Ibídem
} 
2. Casas Viejas. Col. Particular (Málaga), 1971

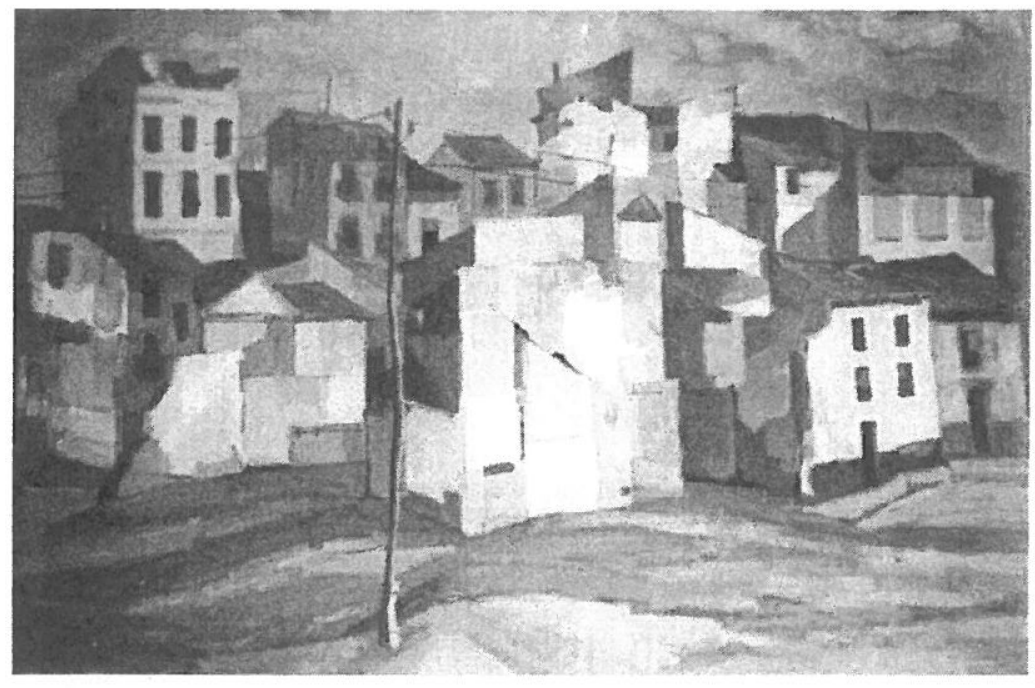

valor de uso, se trascienden a sí mismas para aparecer como meros objetos estéticos, libres de todo conocimiento previo. Esas viviendas agrupadas, dados de ojos y bocas agonizantes en palabras de Garrido Moraga ${ }^{17}$, reclaman, en definitiva, la atención del espectador en su contenida mudez, y aunque su exposición no signifique explícitamente crítica social, un soterrado sentimiento de nostalgia discurre por entre estas paredes quejumbrosas y calles desiertas.

En el primer subgrupo que hemos denominado, «Panorámicas», una primera obra llama poderosamente la atención: Perchel (FiG. 1). Fechada en 1970, de inmediato advertimos su rigor constructivo y su voluntad de cuadricula definida. El motivo se presta a ello: una visión frontal de un edificio bajo, de varias plantas y numerosas habitaciones al descubierto, mostrando las secciones y tabiques interiores. El edificio ocupa todo el espacio, sin apenas resquicios para cielo y suelo, y una alternancia de gamas cromáticas en clara oposición para delimitar las estancias. Esta forma de estructurar la composición es equiparable a las numerosas tentativas pictóricas, en el ámbito nacional, donde se mezclan la necesidad constructiva, herencia del cubismo, y la abstracción disolutiva, bien palpables en la obra de Agustín Redondela (años 60-70), las vistas urbanas de José Lapayese del Río o el postcubismo naturalista de Díaz Caneja ${ }^{18}$. Si tenemos en cuenta las diversas tendencias que circulaban por Málaga en los años setenta ${ }^{19}$, constatamos que López

\footnotetext{
17 GARRIDO MORAGA, Antonio M.; López Palomo. Crítica de arte, folio manuscrito, s.f.

${ }^{18}$ CAMPOY, Antonio María, 100 maestros de la pintura española contemporánea. Madrid, Ibérico Europea de Ediciones, 1976, pág. 202.

19 Eran las siguientes: informalismo, abstracción geométrica, surrealismo, neodadaísmo y figurativismo vanguardista. COLOMA MARTÍN, Isidoro. «La renovación de la plástica malagueña actual» en Málaga, tomo III, Granada, Ed. Anel, 1984, págs. 1019 y ss. Cfr. PALOMO DÍAZ, Francisco J.; «En torno al magicismo. La pintura de vanguardia en Málaga», en PUERTAS TRICAS, Rafael (coord.), Estudios picasianos, vol. III, Centenario-Málaga-Picasso, Madrid, Ministerio de Cultura, 1981, págs. 51-56.
} 
Palomo, sin pertenecer a ningún grupo de vanguardia, permanece atento a los estilos punteros y experimenta sin ningún pudor en la temática perchelera, dentro de un contexto de pintura que se ha denominado «modernidad moderada» ${ }^{20}$.

Acabamos de nombrar a varios integrantes de la llamada Nueva Escuela de Madrid; la cita no ha sido gratuita pues encontramos, salvando las distancias artísticas e históricas, puntos de contacto con la sintaxis que López Palomo aplica en sus temas del Perchel: en la paleta hay un empleo generalizado de las gamas frías que, al ir evolucionando, se hacen calientes progresivamente; empleo de luces fijas, invariables; búsqueda del equilibrio; se procura la síntesis expresiva con la mayor simplicidad formal y estructural; la obra descuella por la interpretación personal del artista, y, entre otras consideraciones, Manuel Sánchez-Camargo, mentor del citado grupo, menciona dos que nos interesan especialmente: el neocubismo empleado en bodegones y paisajes, y la realidad de rescatar una geografía olvidada y perdida ${ }^{21}$.

Por otra parte, aunque ambas características confluyen en la producción de nuestro pintor, sería erróneo equipararlas y plantearlas en el mismo campo de acción de la Escuela de Madrid, pues si bien éstos adjudicaron al paisaje castellano un papel preponderante en sus lienzos, la heterogeneidad estilística de sus miembros rechazaba tal aseveración en tanto que ese paisaje constituyó únicamente un vehículo de modernización pictórica y sólo en casos muy contados - Martínez Novillo, Francisco Arias, San José- se asumió el verdadero "espíritu» de Castilla ${ }^{22}$. No es el caso de López Palomo. La motivación decisiva para recuperar los paisajes de su tierra natal proviene, en sus propias palabras, al sentirse muy identificado con la ciudad en la que he nacido y vivo; tal vez por eso, me atrae, como tema de pintura, la ciudad ${ }^{23}$, sin otros condicionantes de estirpe literaria, anecdótica o crematística.

Con cierta frecuencia, la crítica ha catalogado numerosas obras de esta serie como "cubistas» o «neocubistas» $y$, por añadidura, ha incluido a su autor en una categoría que si bien presenta, a primera vista, algunos rasgos afines, la realidad obliga a una cierta prevención en las atribuciones. Veamos tres nuevos ejemplos: Casas viejas, Casas y Barrio del Perchel. Las dos primeras obedecen a un mismo sistema compositivo: formato horizontal; perspectiva aérea; punto de vista alto, con predominio del suelo sobre el cielo; cromatismo homogéneo, con estudiada

${ }^{20}$ CORREDOR-MATHEOS, José, «El arte de las vanguardias y la modernidad moderada» en Del realismo a la actualidad, Vol.II, Colección Central Hispano, Barcelona, Edita Fundación Central Hispano, 1997, pág. 170.

${ }^{21}$ SÁNCHEZ-CAMARGO, Manuel, Diez pintores madrileños. Pintura española contemporánea. Madrid, Ediciones Cultura Hispánica, 1966, pág. 12.

${ }^{22}$ BOZAL FERNÁNDEZ, Valeriano, Pintura y escultura españolas del siglo XX (1939-1990). Col. Summa Artis, vol. XXXVII, Madrid, Espasa-Calpe, 1992, págs. 196-198.

${ }^{23}$ MAYORGA, José, «Rafael López Palomo, intérprete de la realidad». Sur de Málaga, 6 noviembre-1988. 


\section{Casas. \\ Col. Particular, 1974}

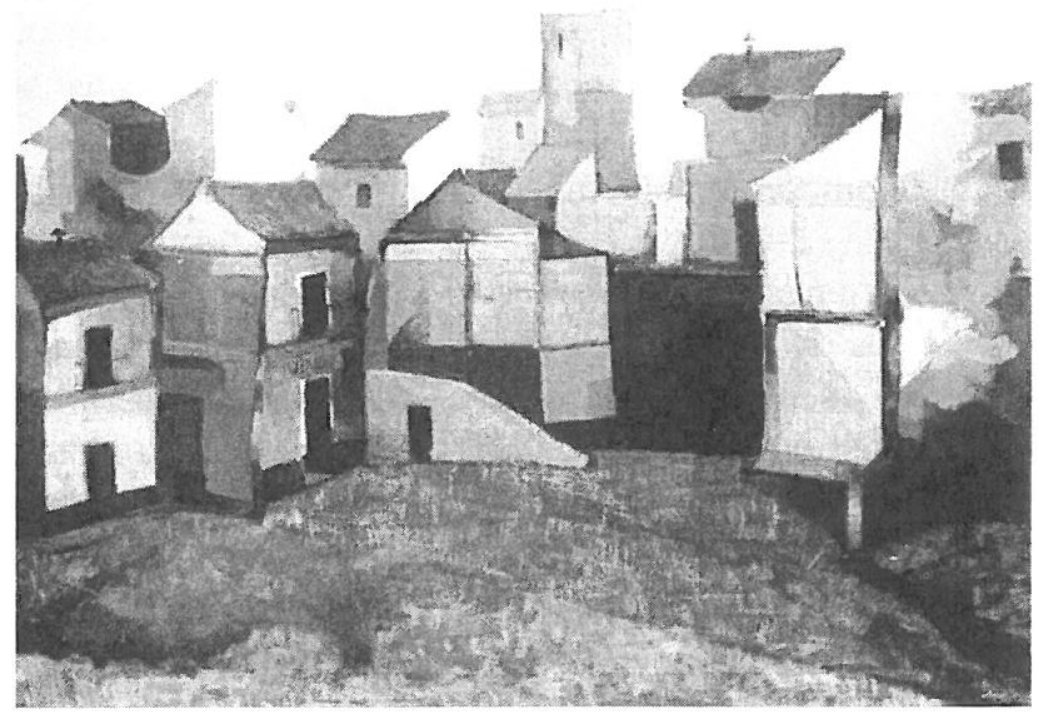

alternancia de zonas cálidas y frías, y luz amortiguada y envolvente. El objeto de representación, las casas, se disponen con relación a los ejes ortogonales y a bandas claras/oscuras que delimitan estancias y cohesionan la composición, delimitando una planimetría, como sucintamente sugirió algún periodista, como conseguida por medio de cuadrados o, tal vez, cubos superpuestos ${ }^{24}$.

Para aligerar la sensación monolítica de fachadas frontales y concatenadas, el pintor aplica dos recursos primordiales: el primero consiste en situar un objeto vertical (un poste de telégrafos) en algún extremo de la escena; con ello, rompe la franja horizontal y continua de casas y establece un punto de perspectiva que establece primeros y segundos términos. En Casas viejas (FIG. 2) el poste abarca las tres zonas de acción (suelo-casas-cielo), fija la profundidad espacial y facilita las distancias. Con su presencia, además, refuerza la esperanza en un panorama abatido y desolador: por esos hilos aún fluyen voces y sonidos, personas que se resisten a abandonar unas casas, como ha escrito Segovia Lobillo, con unos colores que exudan sanguinolentas sensaciones tonales, como si aquellas paredes fueran la piel anónima de tanta gente dentro ${ }^{25}$.

La segunda solución se ofrece con claridad en Casas (FiG. 3), aunque también la apreciamos en la obra antes comentada. La visión en alto posibilita la vista de los pisos bajos, cuyos tabiques a ras de suelo definen movimientos en ángulo recto y se retranquean hasta casi la mitad del lienzo. A ello también colabora la contraposición

\footnotetext{
24 Sur de Málaga, 3-diciembre-1976.

${ }^{25}$ Comentario recogido en Catálogo de la exposición «López Palomo», Málaga, Galería de Arte Benedito, mayo de 1986.
} 


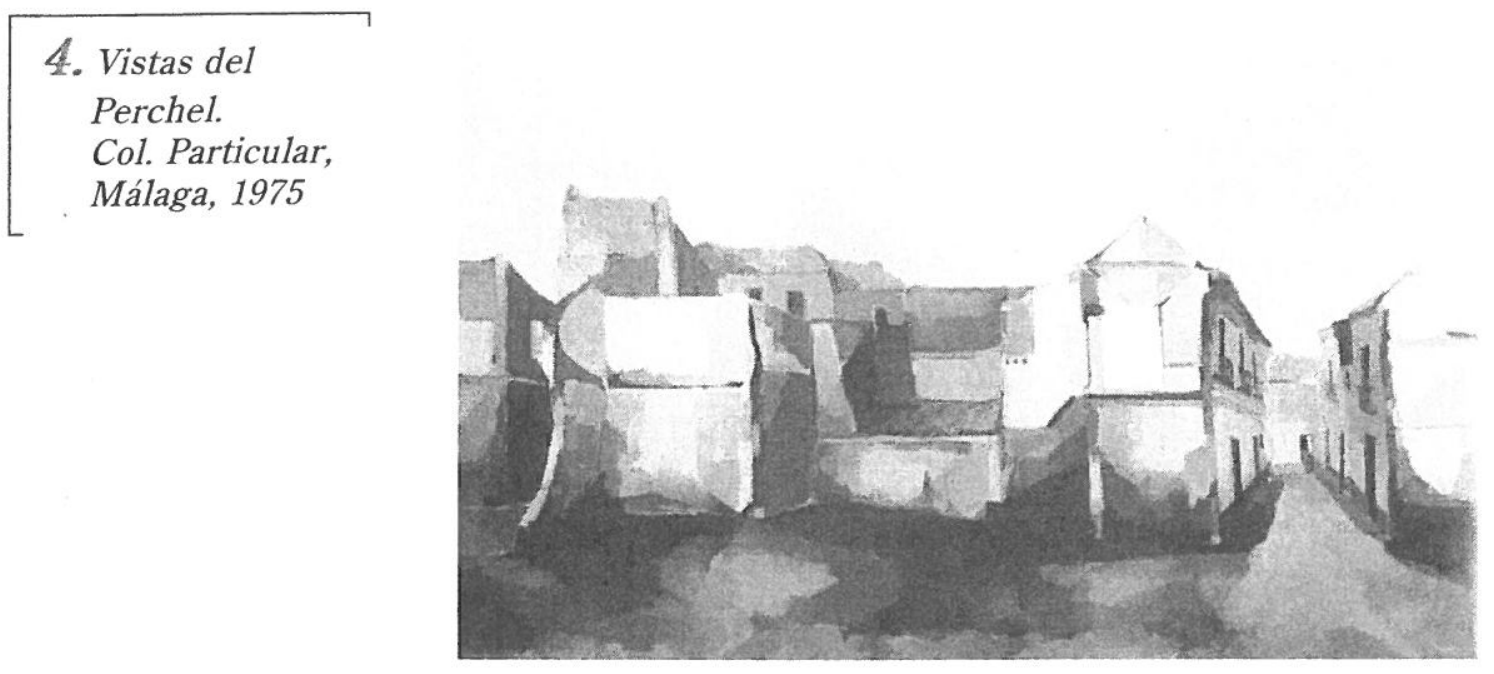

claro/oscuro que, hábilmente utilizada, refuerza la compartimentación de planos en zig-zag. Una variante de este recurso está en Barrio del Perchel, donde la profundidad viene marcada por el impacto visual que supone la cúpula de la iglesia del Carmen, mientras la hilera de casas, en primer plano, contrapone su sólido juego de grises, malvas y rojizos frente a la inestabilidad latente que las amenaza (dinteles reforzados, barandillas inseguras); construcciones que, podríamos pensar, se apoyan unas a otras para no caer.

Así pues, la veracidad de este "personal cubismo» de López Palomo no radica en la descomposición analítica del objeto representado — según los cánones del cubismo primitivo-, sino en una ambigua estructuración cuadrangular que a medida que evoluciona disuelve los contornos en armónicas modulaciones cromáticas; en palabras del profesor Palomo Díaz aparenta estar a un paso de desembocar en una heterodoxia cubista o en una abstracción cromática, sin estarlo nunca en ninguna de las dos ${ }^{26}$. Su preocupación por el volumen y la estructura le lleva a "dar forma» mediante el color, resultado éste de un doble proceso receptivo: por un lado, la sensibilidad intuitiva, que capta de la realidad natural la impresión de un entorno concreto; de otro, la meditación reflexiva, donde templa y corrige esa impresión objetiva y la supedita a la primacía de la sustancia poética. De esta manera, el diálogo entre artista y obra es constante y necesario, pero, sobre todo, es íntimo y razonado. No es descabellado, pues, que recordemos a Cézanne y su particular forma de registrar "la verdad» del mundo real: El paisaje se humaniza, se refleja y piensa en $\mathrm{mi}^{27}$. Semejante inquietud subyace en el Perchel que López Palomo nos describe: un escenario olvidado cuya vitalidad interior renace mediante

${ }^{26}$ PALOMO DÍAZ, Francisco J, «La luz del sur mediterráneo» en AA.VV. Pintura Base 7, Málaga, Ed. de los autores, 1987, pág. 70.

${ }^{27}$ Cita recogida en DE MICHELI, Mario. Las vanguardias artísticas del siglo XX. Madrid, Alianza Forma, 1989, pág. 205. 


\section{Restos del \\ Perchel. \\ Col. Particular, \\ Málaga, 1976.}

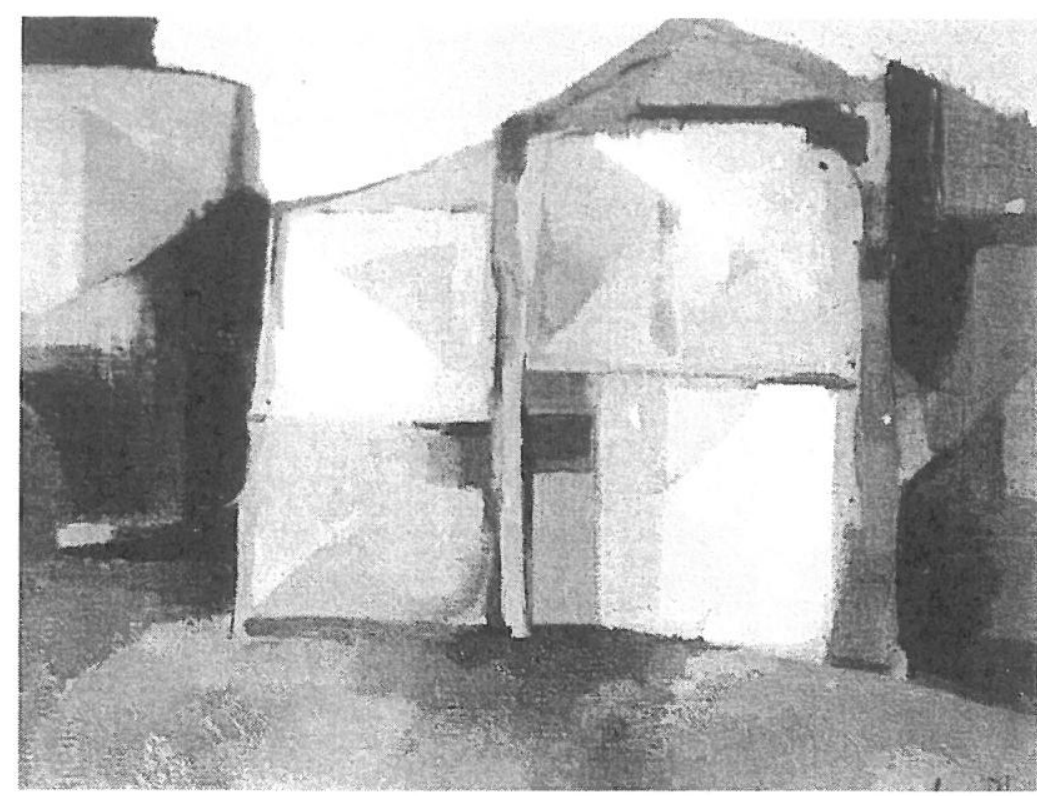

el color, un colorido despojado de toda arbitrariedad casual por el tamiz introspectivo de su creador.

Para concluir con este apartado dedicado a las «Panorámicas", veamos Vista del Perchel (FIG. 4). Datada en 1975, experimenta la evolución plástica arriba citada: los perfiles se diluyen cada vez más en manchas cromáticas y los tonos se compensan entre sí, estableciendo la correspondiente sensación de profundidad y, al igual que el maestro de Aix, lucha con combinar su sentido natural del dibujo plano y su conciencia de la forma sólida ${ }^{28}$. Para romper la linealidad del motivo, introduce en la zona derecha un punto de fuga (una calle que se abre), y así expone dos sistemas de representación en la búsqueda de la modernidad pictórica: la perspectiva lineal y la dicotomía color-forma; rasgos, además, por los que percibimos su sólida aunque disimulada formación académica.

Aunque ya hemos advertido de que el pintor no se integra en ningún movimiento renovador, en las obras estudiadas palpita una característica común a los realismos de vanguardia presentes en la década de los setenta: la intención pictórica ${ }^{29}$. Este concepto, acuñado por Raúl Chavarri, confería a la figuración tradicional, que por aquellas fechas hacía crisis en España, la voluntad de entender la pintura de una manera distinta, incluso utilizando una iconografía de lo más convencional. Se pretendía, en definitiva, superar la mera función transcriptiva de la pintura, algo que López Palomo consigue con su estilo personalísimo y carente de contradicciones.

${ }^{28}$ CLARK, Kenneth, El arte del paisaje. Barcelona, Ed. Seix Barral, 1971, pág. 174.

${ }^{29}$ CHAVARRI, Raúl, La pintura española actual. Madrid, Ibérico Europea de Ediciones, 1973, pág. 138. 


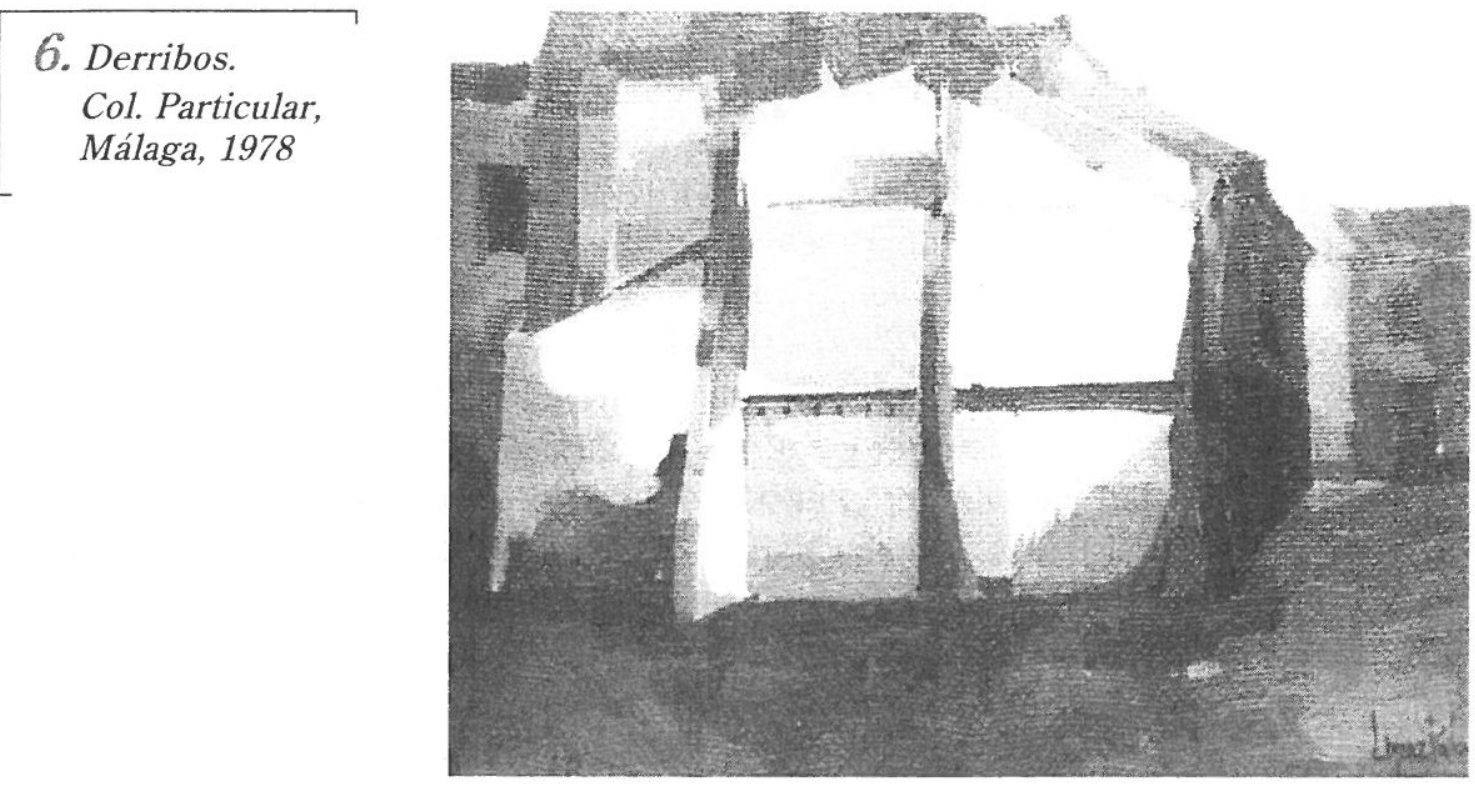

En el epígrafe que denominamos "Casas aisladas" hemos reunido varios ejemplos - menos, ciertamente, que en el apartado «Panorámicas»— pero muy significativos en cuanto a evolución técnica y elementos definidores de un contexto histórico-social muy concreto; un salto cualitativo que ya no es posible definir como algo geométrico de formas ${ }^{30}$, sino que altera, incluso, la concepción mítica del lugar. A este respecto, nos remitimos de nuevo a Segovia Lobillo pues su comentario explicita, sagazmente, la intención primigenia del pintor: sus temas urbanos (...) padecen en ocasiones de desarraigo, no hincan su tiempo en el suelo, aproximándose un poco a piezas recortadas de un falso teorema de la realidad ${ }^{31}$.

Un gran conocedor del Perchel y su historia, Gustavo García Herrera, nos dejó una elocuente descripción de estas casas: planta baja con discreto zaguán; amplia puerta de cuarterón que da acceso al patio; en los laterales del patio se abren las habitaciones de los vecinos de la planta baja, y, por supuesto, la nota colorista que proporcionan las macetas y plantas de jardín que adornan los balcones ${ }^{32}$. ¿Cómo es posible, pues, un cambio tan radical en la representación y, sobre todo, qué metamorfosis interna ha inducido al pintor a esta abstracción perceptiva?

No hay más que ver Restos del Perchel y Derribos para comprobar el axioma (FIG. 5). En ambas el motivo principal son los tabiques interiores de unas casas,

\footnotetext{
${ }^{30}$ DE LA BANDA Y VARGAS, Antonio, De la ilustración a nuestros días. Col. Historia del Arte de Andalucía, vol. VIII, Sevilla, Ed. Gever, 1991, pág. 482.

${ }^{31}$ SEGOVIA LOBILLO, Antonio, Crónica de arte. Radio Nacional de España, folio mecanografiado, febrero de 1979.

${ }^{32}$ GARCÍA HERRERA, Gustavo, Cosas de Málaga. Recuerdos del Perchel. Málaga, Editorial Arguval, 1986, pág. 32.
} 
desnudos de decoración y cuya fisonomía está muy desgastada por los estragos del tiempo y la intemperie. El mínimo espacio reservado al cielo dota al suelo de una importancia básica, como afirmaba el crítico, tanto para la solidez estructural como para el trasfondo temporal. A esta firme estructura hay que añadir un depurado y apropiado cromatismo que reivindica valores que superan la mera ubicación localista y sugiere nociones de validez genérica y universal.

El pintor se desmarca, aún más, de su adjudicado "personal cubismo» y compone mediante áreas de color y enérgicos contrastes tonales, que, sin embargo, no rompen la unidad plástica por la acción de registros compensatorios ${ }^{33}$. La paleta presenta dos alternativas: ocres, pardos y terrosos para definir los bloques colindantes y el suelo; el blanco, sin ser separado de azules, violetas o el gris, cuya presencia confirma la teoría de André Lhote en la que dicho color es, en cierto modo, el soporte, la justificación de toda armonía cromática ${ }^{34}$, organizan y vivifican los paredones centrales. No hay, contra lo que pudiera parecer, dos franjas opuestas entre sí: el pintor mantiene el tono local que homogeneiza la composición y dispone gamas de gradaciones, como sutilmente se percata Rafael Cortés, que llegan a tal identidad de relación para convertirse en creadoras de atmósfera, de correlaciones de proximidad o lejanía ${ }^{35}$.

Un aspecto donde el artista incide sobremanera es en la resultante matérica del objeto representado. Para ello recurre a la cantidad de pigmento a aplicar: en las paredes, la pincelada es generosa en pasta, atildada y persistente, con suaves matizaciones y marcado registro lumínico; en el suelo y edificios anejos, el toque es suelto y envolvente, con amplio recorrido y muy diluido, que permite mixturas valientes y nada convencionales y, además, apreciar la trama del lienzo, cuyo granulado, grueso o incluso arpillera como acontece en Derribos, recalca el sentido de desarraigo que de estas obras emana (Fia. 6).

Con estos planteamientos, López Palomo ya no pinta un lugar concreto, expresa una sensación; sustituye un escenario real y humano por un concepto globalizador y omnipresente. Ese suelo al que tantas veces nos hemos referido se aferra, titánico e implacable, a unas paredes que ya no reflejan unas vivencias pasadas como en la serie «Panorámicas», sino al vacío mudo y absoluto del olvido. Suelos y paredes, no obstante, que se yerguen altivos y desafiantes, estigmatizados por la desesperanza, negando el estertor de lo inevitable, en justo correlato literario con estos versos de otro apasionado cantor de su tierra, Alfonso Canales: Nada se descompone/ sino para ser

${ }^{33}$ Cualidad que, según José Mayorga, parte de un punto de sincronía y mimetismo con lo que observa y le atrae. MAYORGA, José, «La sólida obra de López Palomo». Sur de Málaga, 28mayo-1986.

${ }^{34}$ LHOTE, André, Tratado del paisaje. Barcelona, Ed. Poseidón, 1985, pág. 49.

${ }^{35}$ CORTÉS, Rafael, «López Palomo, artesano del color». Sur, de Málaga, 16-febrero-1979. 
7. Calle del Perchel.

Col.Particular, Málaga, 1980

algo/ nuevo: de alguna forma, en todo lo que ocurra/ estaremos presentes ${ }^{37}$.

Para concluir este estudio sobre el Perchel en la pintura de López Palomo, nos resta por dilucidar las claves de su producción hacia 1980 , época donde, como ya dijimos, decae su interés por esta temática y afloran nuevos con-

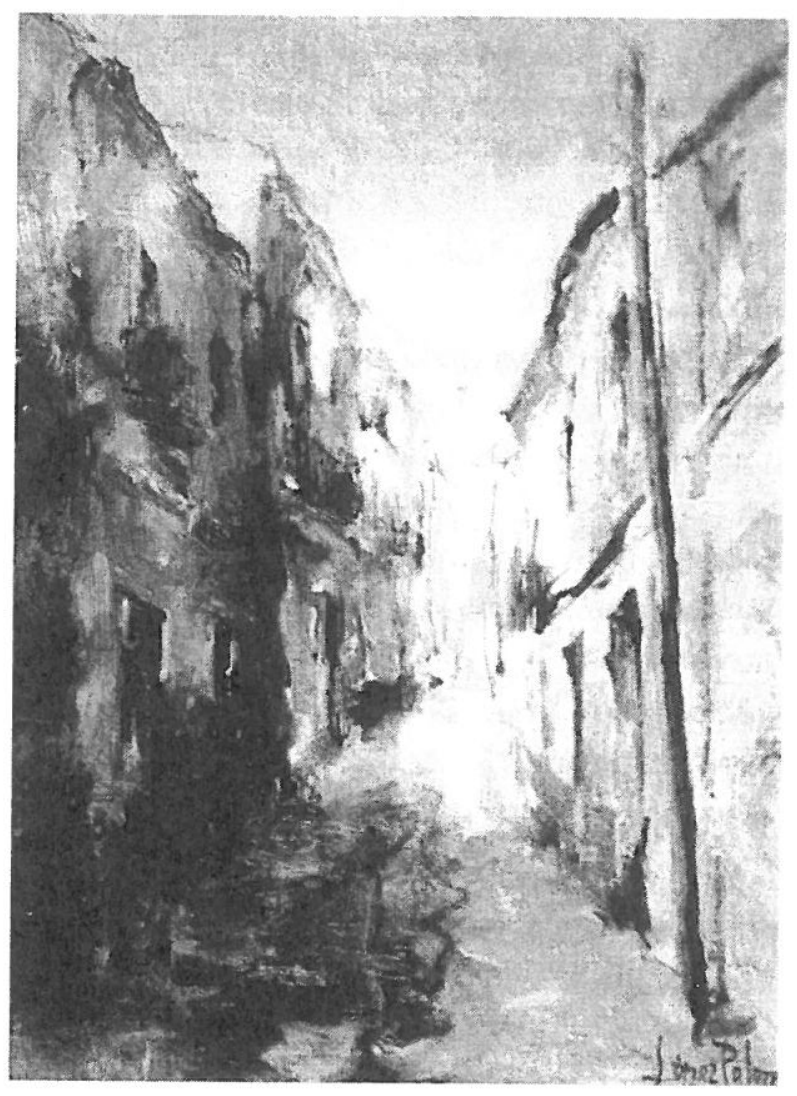
tenidos y motivaciones pictóricas.

Conviene aclarar, antes que nada, que al situar esta etapa «hacia 1980», la acotación cronológica no es tan nítida como parece.

Un confuso período, los años ochenta, donde en el ámbito nacional $-y$ particularmente, Andalucía ${ }^{38}$ - se certifica la muerte de la vanguardia como proyecto y proliferan críticas hacia los valores de la modernidad. La parcela artística experimenta un retorno a la pintura además de la mezcolanza de tendencias y actitudes diversas como el individualismo, la ironía o el eclecticismo ${ }^{39}$. Rige el postmodernismo en toda su amplitud y ello implica el rechazo de comportamientos de carácter informalista y conceptual. En esencia, se pretende una pintura liberada de todo discurso teórico y de todo componente social, y volcada en su propia especificidad ${ }^{40}$. Esta transformación no

\footnotetext{
${ }^{36}$ Similar apreciación comparte Gonzalo Fausto, quien añade: A veces el óleo lo difumina tanto, lo diluye y mezcla con tal maestría que parece un cuadro al pastel. FAUSTO, Gonzalo, «López Palomo, el pintor de la luz mediterránea». El Sol de Málaga, 28-junio-1990.

${ }^{37}$ CANALES, Alfonso, El canto de la tierra. Valencia, Lindes-Cuadernos de poesía, 1977, págs. 62-63.

${ }^{38}$ Para comprobar la multiplicidad de tendencias artísticas, véase Catálogo de la exposición «Andalucía. Arte de una década». Sevilla, Museo de Arte Contemporáneo, del 2 de diciembre de 1988 al 10 de enero de 1989, págs. 9-24.

39 GAMONAL TORRES, Miguel Ángel. «Pintura contemporánea» en Medio siglo de vanguardias, op. cit., págs. 434-5.
} 


\section{Calle Solitaria. Col. Particular, Málaga, 1982}

supuso para nuestro autor cambios sustanciales en su estilo, aunque sí advertimos, desde 1977-78, un imperioso afán por diluir las formas y los contornos, con evidentes ejemplos en el apartado anterior, etapa que se puede dar por finalizada hacia 1983-84 con las últimas realizaciones que destacan un aspecto que no había sido tratado en la década anterior: las calles.

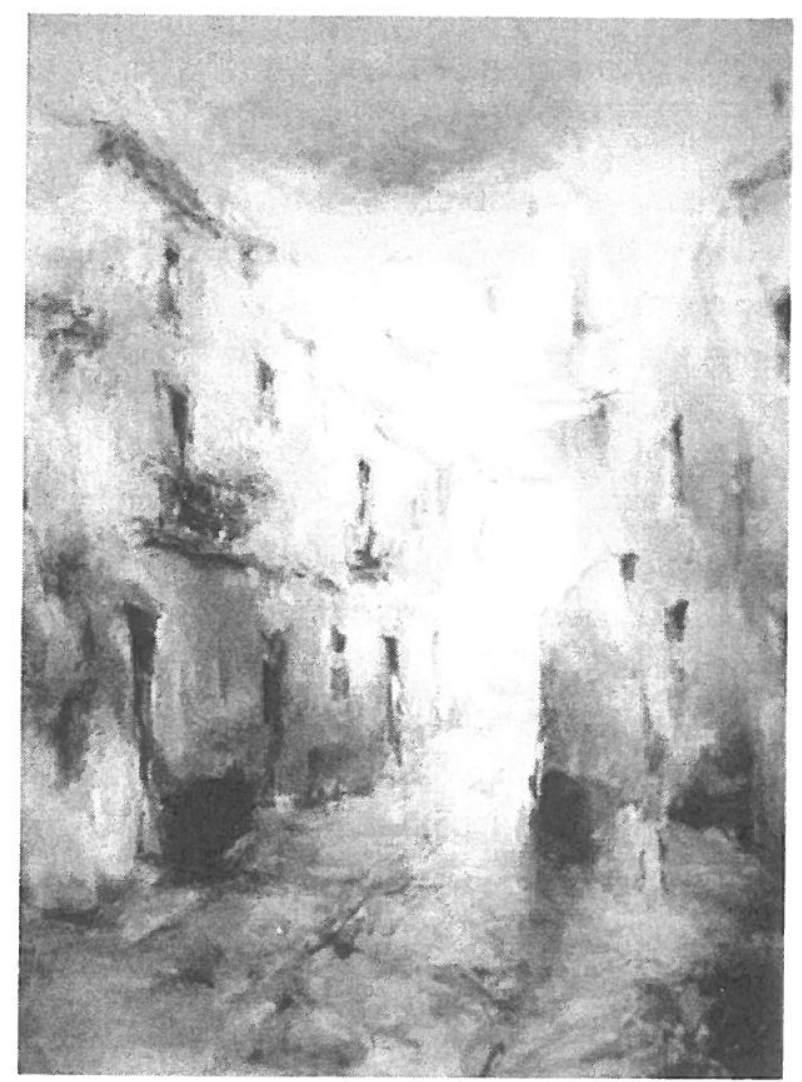

Las obras que he encontrado presentan rasgos similares: en un formato vertical, dos hileras de casas se pierden en perspectiva cuyo punto de fuga dispone una perfecta equidistancia entre los ejes. Sin embargo, y pese a ser un motivo propio para ello, el pintor no utiliza la perspectiva lineal para causar la sensación de profundidad, sino que recurre a la aérea pues el dibujo, aunque existe, queda relegado a un segundo plano, salvo en ciertas matizaciones muy en armonía con el contexto elegido ${ }^{41}$. El colorido es, pues, fundamental, y responsable directo tanto de la plástica como de la estructura compositiva. Prosigue la gama de marrones y terrosos si bien son empleados con mayor intensidad y en zonas concretas del lienzo, demarcando así grandes contrastes de distancia y luminosidad. Prueba de ello es Rincón del Perchel, donde desaparecen los planos concordados de la serie anterior y el color fluye y se refuerza con variadas gradaciones de tono ${ }^{42}$, que interaccionan y yuxtaponen con pasmosa facilidad, transmitiendo, como bien afirma Julián Sesmero, una inquietud colorista no sólo de hábiles maneras, sino de sustanciosos y admirables efectos cromáticos ${ }^{43}$.

\footnotetext{
${ }^{40}$ GUASCH, Anna María. El arte último del siglo XX. Del posminimalismo a lo multicultural. Madrid, Alianza Forma, 2000, pág. 300.

${ }^{41}$ Patria, diario de Granada, 13-diciembre-1980.

42 Sur de Málaga, 3-febrero-1992.

43 Sur de Málaga, 5-septiembre-1995.
} 
Un paso más en esta desintegración formal constituyen los dos últimos ejemplos: Calle del Perchel y Calle solitaria. En el primero (Fig. 7), una suerte de temblor inmanente recorre el angosto pasaje gracias a la viveza cromática utilizada, cuya habitual presencia de ocres y tierras se intensifica con estratégicas aportaciones de azul cobalto y rojo inglés, $y$, principalmente, debido a la extrema ligereza y fluidez en la pincelada, artífice indudable de la atmósfera silente e insondable que deriva del lienzo. La ausencia de todo aditamento superfluo o referencia figurativa accesoria acentúa en el pintor su tendencia, cada vez más, a la simplificación o, como bien dice el profesor Gómez Yebra, a encontrar la mancha sin amaneramiento, a la abstracción de lo concreto; una cualidad, empero, que precisa una sobresaliente capacidad de síntesis pero también de sensibilidad, atributos propios de un moderno arúspice prosigue el citado autor- que desentraña cada ambiente y nos proporciona su interpretación genuina ${ }^{44}$.

El lienzo titulado Calle solitaria (FIG. 8) simboliza el caso más extremo en la intención de López Palomo por sugerir más que representar. Una suave cadencia cromática unifica la composición y envuelve la escena en una vaporosa intangibilidad de siluetas. Las zonas puntuales de color -rojizos en las paredes y destellos azulados del agua en el pavimento- dirigen sabiamente la mirada hacia el fondo de la calle y encuentran su íntima expresión en unas casas, lejanas y evanescentes, semejantes a un rincón de paz, una especie de isla espiritual, donde, como dijo el poeta, se encuentra uno consigo mismo, donde uno dialoga con su misteriosa sombra que le ayuda a crear belleza ${ }^{45}$.

Al contemplar estos óleos, resulta inevitable recordar la similitud estilística con otro pintor, en este caso madrileño, Eduardo Vicente, de quien Gaya Nuño no sólo ponderaba el encanto singular de pintura tan sugerida y tan segura, tan leve y ligera, sino también su profundo y contenido lirismo $\mathrm{O}^{46}$, virtudes igualmente atribuibles a nuestro artista. Una vez más, vemos como López Palomo soluciona de forma satisfactoria su dialéctica con el entorno cotidiano: elimina todo barroquismo inconsistente, toda suerte de resortes parafernalios en pro de la esencia misma de las cosas, o, como afirma otro pintor también preocupado por la esencialidad, Ramón Gaya, "salvar la realidad ${ }^{47}$, cometido para el que se reafirma con sus dos principales cualidades: sencillez expositiva y sobrados recursos técnicos.

En un escrito de 1973, Vicente Aguilera Cerni prodigaba las invectivas contra las corrientes que, por aquellos años y según su opinión, inequívocamente comportaban

\footnotetext{
${ }^{44}$ GÓMEZ YEBRA, Antonio A, «Reflexiones sobre pintura» en Catálogo de la exposición «López Palomo». Málaga, Galería de Arte Benedito, enero de 1992.

${ }^{45}$ SALAS Y GUIRIOR, José, Buenas noches. Málaga, Artes Gráficas Alcalá, 1956, pág. 120.

${ }^{46}$ GAYA NUÑO, Juan Antonio, La pintura española del siglo XX. Madrid, Ibérico Europea de Ediciones, 1970, pág. 337.

${ }^{47}$ GAYA, Ramón. Obra completa. Tomo I, Valencia, Pre-Textos, 1990, pág. 83.
} 
la negación de la 'artisticidad' del arte. Asimismo añadía, como único consuelo esperanzador, que el arte hecho por los 'artistas' vegeta de modo marginal, circunscrito al microcosmos del consumo minoritario ${ }^{48}$. No nos compete debatir esta postura - personal y subjetiva, en todo caso-, pero sí nos interesa vincularla al pintor cuya obra hemos visto en las páginas precedentes. Con su particular visión del Perchel, López Palomo arrebata al tiempo su implacable olvido y devuelve el protagonismo a una zona castigada por la desidia y el abandono; un barrio celebérrimo que grita sus últimos quejidos a través de paredes macilentas y calles desahuciadas; un escenario de ruinas y desolación orgulloso de su pasado y que artistas como Rafael López Palomo dignifica y eleva a la categoría de arte para un consumo, minoritario o no, que elogia las virtudes de su creador.

Un homenaje, en definitiva, a unas raíces, a unos recuerdos compartidos por muchos malacitanos, rescoldos emotivos que perviven en la conciencia colectiva de un pueblo y que tienen en estos versos de Alfonso Canales su más sincera e inmediata expresión ${ }^{49}$ :

Portales desolados

azoteas sin sábanas tendidas,

jaulas, barandas, rejas desprendidas,

tabiques acostados

donde alzaba la vida sus cuarteles,

patios sin voz, guitarras sin cordaje,

oscuras golondrinas sin viaje

de regreso, macetas sin claveles.

${ }^{48}$ AGUILERA CERNI, Vicente, Posibilidad e imposibilidad del arte. Valencia, Fernando Torres

Editor, 1973, pág. 189.

${ }^{49}$ CANALES, Alfonso, «Elegía del Perchel». Texto recogido en GARCÍA HERRERA, Gustavo.

Cosas de Málaga..., op. cit., págs. 9-10. 